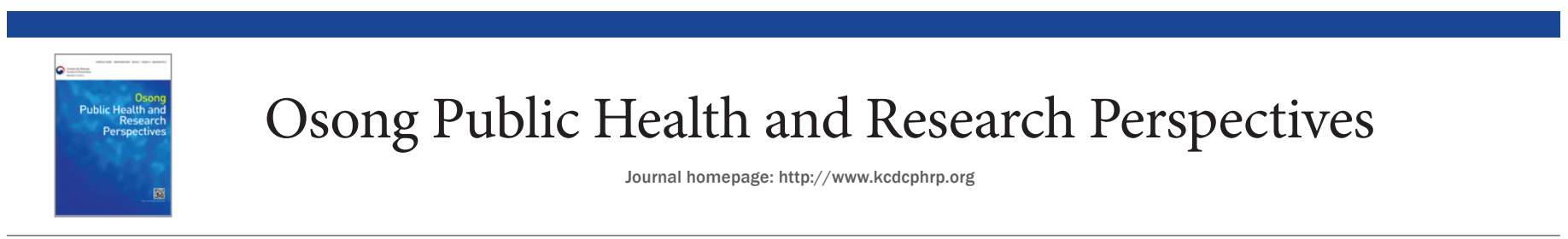

Editorial

\title{
Gone with the Wind
}

\author{
Hae-Wol Cho a,b,* \\ a Osong Public Health and Research Perspectives, Korea Centers for Disease Control and Prevention, Cheongju, Korea \\ ${ }^{b}$ College of Medicine, Eulji University, Daejeon, Korea
}

https://doi.org/10.24171/j.phrp.2019.10.2.01 pISSN 2210-9099 eISSN 2233-6052
Passive smoking is the inhalation of second-hand smoke (SHS) by persons other than the "active" tobacco smoker. This exposure to SHS may cause disease, disability, and death [1]. Passive smoking has been shown to be associated with the same diseases as active smoking (such as cardiovascular diseases, lung cancer, and respiratory diseases) [2]. Analysis of the effects of SHS has come from studies of nonsmokers who are married to a smoker, with similar findings also reported in studies of workplace exposure to tobacco smoke [3]. SHS consists of mainstream smoke (the smoke exhaled by a smoker) and sidestream smoke (the smoke released from a cigarette into the surrounding air) [4]. The main component of SHS is sidestream smoke, which is about 4 times more toxic than mainstream smoke [5], and has the most impact on the health of passive smokers [6].

Looking forward, an objective of the Health Plan 2020 (HP2020) in Korea is to lower the exposure to SHS for those individuals who do not smoke tobacco by assigning designated non-smoking areas in public places in Korea such as squares and city parks [7]. This supports the National Health Promotion Act (2017) which prohibits smoking in all middle and high school facilities, and smoking bans in college classrooms [8].

Previous studies on the exposure to SHS have generally focused on the subjective reports of study participants regarding their exposure to SHS [9]. Most studies lack the quantitative measurement of biomarkers of exposure to SHS such as cotinine, and nicotine-derived nitrosamine ketone in urine. The measurement of cotinine in hair and urine is accurate, and non-invasive, and is an effective indicator of exposure to SHS [1].

In the current issue of Osong Public Health and Research
Perspectives, a study by Park et al. measured the exposure to SHS amongst non-smoking, nursing college students, by measuring urinary cotinine, and analyzed the demographics, health, and smoking-related factors that may influence exposure to SHS [10]. This cross-sectional study examined nursing college students $(N=196)$ who had not smoked tobacco in the previous year. To measure the exposure to SHS in students, the authors examined urinary cotinine levels, and social factors that may be influential, such as asking a smoker to put out their cigarette. The study observed that 32 students (16.3\%) had urinary cotinine levels suggestive of exposure to SHS. There were 80 students (40.8\%) affected by risk factors that increased exposure to SHS. In addition, students who were exposed to SHS were 4.45 times more likely to have increased urinary cotinine levels. It was reported that students who asked smokers to extinguish their cigarette, were 0.34 times less likely to test positive for urinary cotinine.

The authors concluded that non-smoking, nursing college students, that displayed self-assertive behavior by requesting smokers to extinguish their cigarette, could avoid exposure to SHS. It was also suggested that systematic support for the enforcement, and expansion of no-smoking zones, should be a requirement in all college facilities.

\section{Conflicts of Interest}

The author declares no conflicts of interest.

* Corresponding author: Hae-Wol Cho

College of Medicine, Eulji University, Daejeon, Korea

E-mail: hwcho@eulji.ac.kr

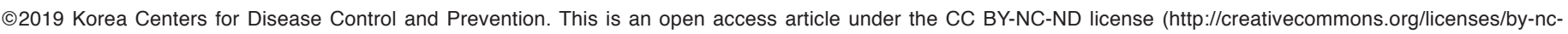
$\mathrm{nd} / 4.0 /$ ). 


\section{References}

[1] Lim SG, Kim JY, Lim WR, et al. Review of various quantitative methods to measure secondhand smoke. Korean J Environ Health Sci 2009;35(2):10015.

[2] Schick S, Glantz S. Philip Morris toxicological experiments with fresh sidestream smoke: More toxic than mainstream smoke. Tobacco Control 2005;14(6):396-404.

[3] Wells AJ. Lung cancer from passive smoking at work. Am J Public Health 1998;88(7):1025-9.

[4] Sohn HJ, Oh AR, Kim OG, et al. Secondhand smoke exposure in commercial personal computer rooms. Korean J Environ Health Sci 2010;36(4):28893.

[5] Schick S, Glantz SA. Sidestream cigarette smoke toxicity increases with aging and exposure duration. Tobacco Control 2006;15(6):424-9.
[6] Park MA, Kim MY, Ha YS. Effectiveness of a secondhand smoking prevention program on adolescents. J Korean Acad Community Health Nurs 2014;25(1):44-53.

[7] Ministry of Health and Welfare [Internet]. Social Guarantee in Statistics. 2015. Available from: http://www.mohw.go.kr/front_new/ jb/sjb030301vw.jsp?PAR_MENU_ID=03\&MENU_ID=0319\&CONT SEQ=330479\&page $=1$.

[8] National Health Promotion Act [Internet]. 2017. Available from: http:// www.law.go.kr/lsInfoP.do?lsiSeq=188082\&efYd=20170603\#0000

[9] Kim MS, Kim YH. A study on the assertive behavior among non-smoking college students under secondhand smoke exposure. J Korea Acad Industr Coop Soc 2012;13(11):5187-95.

[10] Park SA, Lee DH, Lim HS. Factors influencing exposure to secondhand smoke: passive inhalation in student nurses. Osong Public Health Res Perspect 2019;10(2):78-84. 